\title{
Index des auteurs/Index des matières
}

Aiach, M. 87 Aillaud, M.F. 16 Bassand,J.P. 135 Becque, O. 135 Bellens, B. 79 Berland,J. 127

Besse, P. 94 Bonnet, J.L. 90, 145 Bricaud, H. 90 Brochier, M. 62 Brottier, L. 90 Cardot, J.C. 135

Cella, G. 54 Cerene, A. 83 Charbonnier. B. 62 Colle, J.P. 90,94 Collen, D. 3, 26 Conard.J. 35

Cribier, A. 127 Delcour, C. 79

Dereume, J.P. 79 Desveaux, B. 62 Elias, A. 69 Faivre, R. 135 Fiessinger, J.N. 87 Francois, G.

62 Ganz, W. 117 Garcez, J.L. 79 Gamier, L.F. 62 Gaux, J.C. 87 Giraud, C. 83 Griguer, P. 62

Guize, L. 110 Habert. Ch. 135 Horellou, M.H. 35 Joffre, F. 83 Juhan-Vague, I. 16 Laroze, M.

135 Lecomte, T. 110 Lecorff, G. 69

Ledain. L. 94 Letac, B. 127 Lew. A.S. 117 Lijnen, H.R. 3, 26 Lorient-Roudaul, M.F.

94 Maurat,J.P. 135 Mclntyre, K.M. 54 Moore, N. 127 Morand. Ph. 153 Nguyen, G. 35 Ohayon.J. 94 Pâques, E.-P. 21 Pernes, J.M. 87 Petiteau. P.Y. 135 Philip. F. 69 Puel, P. 83 Raynaud, Ph. 62 Redonnet. M. 127 Richard, J.L. 110

Roncato. M. 87 Roudaut, R. 94 Sainsous. J. 110, 145 Samama, M. 35 Saoudi, N. 127 Sasahara. A.A. 54 Schuffenecker. M. 135 Serradimigni. A. 1,16,

69, 110, 145 Sharma.G.V. 54 Struyven, J. 79 Tanielian, P. 110 Trübesteín, G. 40 Verdenet. J. 135 Vincent. G. 79 Vitoux.J.F. 87 Wautrecht. J.C. 79 Witchitz. S. 106

Activateur tissulaire du plasminogène 3, 26 Actosolv Urokinase 156 Acyl-enzymes 35 Alpha-2antiplasmine 16 Antistreptokinase 16 Anti-t-PA 16

- $\quad$-UK 16

Artériopathie 87, 90

Défibrase 62

Doppler veineux 69

Echocardiographie 69

Echographie vasculaire 69

Embolie pulmonaire 54, 62, 69

Enquête nationale 110

Essai randomise 145 Fibrinolyse 3, 16,21,90,94

- $\quad$ loco-régionale 79

Héparine 54,69, 135, 145 Infarctus aigu du myocarde 117. 127

- $\quad$ du myocarde $110,135,145$

Inhibiteur anti-activateur 16

Interruption partielle de la veine

cave inférieure 69 Ischémie aiguë 79, 90 Lys-plasminogène 83 Lysyl-plasminogène 62 Maladie

post-phlébitique 69

- $\quad$ thromboembolique

postphlébitique 40

Necrose 117 Phlébographie 69 Prothèses valvulaires 94, 106 Pro-urokinase 3. 35 Récidive embolique 69 
Revascularisation 79 Stenoses 90

Streptasc (Streptokinase) 158 Streptokinase 3, 21, 54. 62, 79, 94, 106, 145

intracoronarienne 117,127

intraveineuse $110.117,127,135$

Thrombolyse 3. 26. 35. 62

endogène 54 Thrombolytique(s) 40, 69. 87 Thrombose(s) 83.94, 106

veineuse 69 Thrombus intracardiaque 69 Urokinase 21, 54, 62, 83, 94. 106 